\title{
The surgical sales representative: examining a new role in urogynecology
}

\author{
Catherine A. Matthews
}

Received: 20 October 2008 / Accepted: 24 October 2008 / Published online: 14 November 2008

(C) The International Urogynecological Association 2008

The face of the gynecologists' sales representative is expanding from the all-too-familiar attractive, well-dressed, female office representative to include a new breed with a slightly different look. This is the young surgical device representative who is stereotypically male, muscular, tanned, and aggressive about "being there to observe a surgical case." I was first introduced to this idea of case observation when a confident man in surgical attire approached me on my way into the operating room and asked if he could watch my scheduled cases that morning. I didn't quite know what to say. How had he gained access to my schedule? Who had admitted him to the surgical suite? What exactly did he want to accomplish by being there? Did HIPPA exist? This was the first of many subsequent encounters initiated by him and his competitors, all vying to somehow get into my operating room "to provide support."

The presence of surgical device representatives in the operating theatre is increasingly common as surgical technologies become more complex and innovative. An anonymous survey of senior nurses in charge of surgical suites in the UK found that device representatives visited operating departments approximately every 2 weeks and attended actual operations every 10 weeks. Only $42 \%$ of units surveyed reported obtaining patient consent for visits and $82 \%$ had no existing guidelines for this process [1]. No published data currently exist regarding standards and procedures for surgical representatives in the USA.

How and why have urogynecologists become a targeted demographic for this new breed of salesman? Two reasons

C. A. Matthews $(\bowtie)$

Virginia Commonwealth University Medical Center,

Richmond VA 23298, USA

e-mail: cmatthews2@mcvh-vcu.edu seemingly exist. Firstly, in this era of expensive surgical "kits" and materials with little data demonstrating superiority of any, much less one over the other, for the treatment of pelvic organ prolapse, the responsibility to move the product rests squarely on the broad shoulders of the device representative. The ability of a sales representative to exert some pressure both in and outside the operating room as they tout the usefulness of their new product likely translates into significantly more sales of one brand over the other.

The second reason, however, is potentially more alarming. As technology evolves and new materials and devices are rapidly introduced into the market, surgeons may elect a procedure with which they have no clinical experience. In an editorial regarding the introduction of new surgical procedures, Gates raises the important question of how surgeons should approach the balance to learn new skills with the fundamental obligation to benefit his or her patients and avoid harm [2]. She astutely points out that no surgical approach can benefit a patient if her surgeon has not yet acquired adequate knowledge about the procedure and the skill necessary to perform it safely. Following completion of a single half-day cadaver course prior to placement of a new kit product, the device representative may serve as a valuable and necessary resource for which anatomic landmarks to identify and how exactly this arm and that trocar all fit together.

How does someone with no medical degree and certainly no live surgical training morph into a resource for troubleshooting and direction during a surgical procedure? Because, in reality, they probably have far more experience with their particular product than you do. They have completed a rigorous training curriculum on models and cadavers and carry with them tips and tricks learned from watching other surgeons battle through the learning curve of 
a new operation. The American College of Surgeons recognizes that sometimes, sales representatives' training and expertise can provide technical assistance that expedites the procedures and facilitates desired patient outcomes [3].

Dependence on individuals with technical expertise but no medical training, however, can have catastrophic results. In a highly publicized ambulatory surgery incident involving a new piece of equipment for endometrial ablation, a woman died of excessive infusion and absorption of normal saline. The New York State Department of Health discovered that the surgeon was using the device for the first time without formal instruction and that an unauthorized individual was allowed to put on scrubs and give direction to the surgeon and nursing staff. The patient had not been informed that a sales representative would observe or participate in the procedure [4].

The public is now aware of the array of opportunities that exist for pharmaceutical companies to influence physician practice and prescribing patterns. We seem to have drawn the line at allowing a drug representative into a consultation room to "observe" our skills interviewing and examining a patient. Is this because the patient is awake and might question the inherent conflict of interest that the situation presents? They are there to sell their product, not advocate for the best choice for the patient. One has to then ask why the standards are any different when the patient is in a more vulnerable position, under anesthesia, in an operating room?
Full disclosure is warranted. We should obtain consent from the patient before allowing a surgical device representative to be present during a case. In a best-case scenario, we should be able to explain to a patient why we have selected a particular product and what purpose the device representative serves by being there. We should not feel pressured to "deliver" a certain number of sales by the constant looming presence of more and more representatives in the hallways of our surgical suites. Perhaps we should even be familiar enough with the "kit" to feel confident placing it in a patient without the helpful assistance of the surgical sales representative. We as surgeons should proactively reform and regulate this emerging conflict of interest before a public outcry is voiced.

\section{References}

1. Sillender M (2006) Can patients be sure they are fully informed when representatives of surgical equipment manufacturers attend their operations? J Med Ethics 32(7):395-397

2. Gates EA (1997) New surgical procedures: can our patients benefit while we learn? Am J Obstet Gynecol 176(6):1293-1298, discussion 1298-9

3. American College of Surgeons. Statement on health care industry representatives in the operating room. http://www.facs.org/fellows info/statements/st-33.html

4. Murphy EK (2001) The presence of sales representatives in the OR. Aorn J 73(4):822-824 